\title{
Implementing a National Virtual Library for Higher Institutions in Nigeria
}

\author{
By Ezra Shiloba Gbaje \\ Shiloba@yahoo.com \\ Department of Library and Information Science \\ Ahmadu Bello University, \\ Zaria Kaduna State \\ Nigeria
}

\begin{abstract}
The Virtual Library provides access to tools such as databases, electronic journals, alerting services, online reference tools, and quality-selected web resources that improve the quality of teaching and research. Unfortunately various virtual library initiatives in Nigeria within the past six years have remained a mirage. This desk study examined the national library virtual project initiatives and identifies the challenges of its implementation within the Nigerian context. Misconceptions of what constitute a virtual library, unavailability of the basic information infrastructure, poor policy implementation and lack of web technologies skilled digital/systems librarians have been identified as some of the challenges in the implementation of the national Virtual Library Project. The study also highlights the process of building a virtual library, collection development, acquisition and access of electronic resources in the virtual library, which are the basic skills required for the deployment and sustainability of the national virtual library.
\end{abstract}

\section{Introduction}

The inability of the Nigerian government to stock libraries in the academic institutions with relevant information resources has great implications for learning, teaching, research and development. Realizing this, the Nigerian government has been making deliberate efforts through the National Universities Commission (NUC), National Virtual Library initiatives and by formulating and implementing relevant information and communication technology policies to facilitate access to relevant and current information for teaching, learning research and development. A Virtual library provides value-added solutions for 
all higher education institutions and facilitates on-line access to an enormous current volume of academic information. Ya'u (2003) asserts that the virtual library has an opportunity to address the scarcity of teaching and research materials in the libraries of institutions of higher education in Nigeria. An indigenous virtual library would allow the institutions and indigenous researchers to share their own research outputs with the global community as well as ensure the preservation of Nigerian cultural heritages. Okebukola, in Russell and Dlamini (2002), argued that a virtual library would improve the quality of teaching and research through the provision of current e-books, journals, and other library resources. It will also enhance scholarship, research and lifelong learning through the establishment of access to shared global virtual archival collections.

The NUC was shouldered with the task of building a National Virtual Library Project that will enhance access to locally-available resources and international library collections for sharing with university libraries all over Nigeria using digital technology. Other functions of the National Virtual Library Project as cited by NUC are:

i. to improve the quality of teaching and research in institutions of higher learning in Nigeria through the provision of current books, journals and other library resources;

ii. to enhance access of academic libraries serving the education community in Nigeria to global library and information resources;

iii. to enhance scholarship, research and lifelong learning through the establishment of permanent access to shared digital archival collections;

iv. to provide guidance for academic libraries on applying appropriate technologies used in the production of digital library resources; and

v. to advance the use and usability of globally distributed, networked information resources.

However, six years after the project was initiated the Virtual Library is yet to be functional. Hence, none of the functions set out has been achieved. This desk study reviewed the NUC National Virtual Library initiative with a view to identifying the challenges to its successful deployment and sustainability, and suggests a way forward. 


\section{Virtual Library}

There have been a lot of misconceptions about what a virtual library is: some consider the World Wide Web as a virtual library, while others consider the collection of URLs on a webpage a virtual library. A virtual library provides access to tools such as databases, electronic journals, alerting services, electronic reference, and quality-vetted e-resources. The term electronic library, digital library and virtual library have been used synonymously. However, there exists some basic difference as noted by Tenant (1999, np.) who posits that an electronic library consists of electronic materials and services such as video tapes and CD-ROM, while a digital library consists of digital services and materials that are stored, processed and transferred via digital (binary) devices and networks. The Virtual libraries on the other hand consist of both digital and electronic libraries existing virtually.

Digital libraries can exist without a virtual library but virtual libraries can not exist without digital libraries. A virtual library provides remote access to digital collections such as electronic documents, digitized pictures, sound, and video. The Digital Library Federation defined digital libraries as

organizations that provide resources, including the specialized staff, to select, structure, offer intellectual access to, interpret, distribute, preserve the integrity of and ensure the persistence over time of collections of digital works so that they are readily and economically available for use by a defined community or set of communities (Waters, 1998, np.).

Based on the Digital Library Federation's definition, Cleveland (1998) listed the following as characteristics of a digital library:

- digital libraries are the digital face of traditional libraries that include both digital collections and traditional, fixed media collections. So they encompass both electronic and paper materials.

- Digital libraries will also include digital materials that exist outside the physical and administrative bounds of any one digital library.

- Digital libraries will include all the processes and services that are the backbone and nervous system of libraries. However, such traditional processes, though forming the basis virtual library work, will have to be revised and enhanced to 
accommodate the differences between new virtual media and traditional fixed media.

- Digital libraries ideally provide a coherent view of all of the information contained within a library, no matter its form or format.

- Digital libraries will serve particular communities or constituencies, as traditional libraries do now, though those communities may be widely dispersed throughout the network.

- Digital libraries will require both the skills of librarians as well as those of computer scientists to be viable.

A virtual library facilitates access to information resources such as databases, electronic journals, alerting services electronic reference tools, and quality-vetted eresources. These resources will need to be managed by librarians and information professionals who understand information needs and users. Traditional library services such as reference work, dissemination, library instruction, and access to information resources are facilitated by a virtual library without confinement to a particular institution or geographical area. This presents new opportunities for drawing much broader boundaries in defining a library's organization and scope of responsibility.

\section{Building a Virtual Library}

The building blocks for a virtual library are its digital collections, which are not just a random assemblage of digital objects or uniform resource locators of free web- based resources (URLs). Building digital collections requires traditional library skills, in addition to information and web technology skills. The process of building a virtual library includes:

\section{a. Digitization}

Digitization involves the process of making non-digitally created materials available in digital format. The retrospective conversion of printed library cards into a machine-readable catalog represents one of the earliest digitization processes librarians have been involved with. The digitization process includes 
selection of collection/materials; scanning, transcribing, and creating markup and an index, creating metadata, quality control by subject specialists, processing images, populating the appropriate digital asset management software (DAM). Digital assets software such as DSpace, Eprints, Fedora, and Greenstone collect, index, and provide queries over a catalog of metadata records that are accessible locally and remotely.

\section{b. Acquisitions and Collection Development}

Acquisition involves acquiring and securing ownership of electronic resources such as databases, e-books and journals through licence. Subscribed electronic resources are stored on a remote server hosted by the vendor and made accessible to a target community after authentication and authorization.

Digital collections of information resources involve selection and organization based on an explicit collection development policy that addresses the information needs of a particular community. Storage and retrieval of digital resources for a virtual library is exclusively dependent on computers and electronic-network systems, hence in selecting materials, basic information on the hardware and software needed to access the resources and existing technology within the library must be taken into consideration.

A virtual library collection is based on an established collection development and acquisition policy which takes into account the shift from owning information resources to licensing information and the aggregation of information in multidisciplinary databases. The difficulty of evaluating and comparing electronic resources makes it necessary to have an electronic collections selection team. Pettijohn and Neville (2003) suggest that members of electronic selection team should possess both functional and subject area expertise. Free web-based, open access, and fee-based resources which require acquiring and securing ownership of digital content through license should be part of a virtual library collection, however, Pitschmann (2001) posits that open access Internet sites are 
fundamentally different from commercially produced resources. Therefore, these collections require their own practices, policies, and organizational model.

\section{Enabling Technology for Virtual Library}

Virtual library services and digital resources are delivered over the Internet which depends on network operating systems running on web server computers. The enabling technologies deployed in a virtual library are web-based technologies that include web design using Hypertext Markup Language (HTML), Extensible Markup Language (XML), cascading style sheets (CSS), $\mathrm{PHP}^{1}$ coding, and web scripting languages such as JavaScript. Virtual library applications depend on relational databases for organization, storage and retrieval of information. Similarly, web scripting languages work in concert with relational databases by sending queries to the databases and then processing the return data. Relational database management systems are installed on the web server hosting the virtual library, some popular relational database management systems includes MySQL, Oracle, PostgreSQL, and Microsoft SQL server.

Virtual library web servers are specially configured to authenticate users as they access various areas of the virtual library and run many applications that are crucial to delivering of services and digital resources. Popular web servers used by most organizations are Apache server and Microsoft's Internet Information Server (IIS). Web servers deliver web pages on request, provide essential tools for routing users to resources on a website, encrypt sensitive data, provide authentication to sensitive areas of a website and provide support for special web server extension or modules used by digital library software. (Dahl, Banerjee and Spalti, 2006).

Storage of electronic resources is either on a local server maintained by the library or parent institution of the library or on a remote server hosted by the vendor. Limits of network bandwidth and slow transmission speeds may make the effective access to virtual library resources problematic for many users.

\footnotetext{
${ }^{1}$ a powerful server-side scripting language for creating dynamic and interactive websites.
} 
One of the challenges to providing access to subscribed material will be how to handle access to subscription-based databases and aggregator services for journals and textbooks. Many vendors restrict access to IP address and require authentication of institutionally affiliated computers or remote users to access subscribed resources. Authentication can include automatic login username and password, automatic login using IP address, library authentication, and the use of proxy server. A proxy server provides remote access to IP restricted resources. After the proxy server authenticates and authorizes the user, it retrieves the restricted resource using the server's IP address and sends it to the user who is browsing from an un-authenticated IP address. Hanson A. and Levin (2003) assert that library authentication, proxy access and IP range authentication are preferable to the use of passwords.

\section{Nigeria National Virtual Library Project}

To facilitate the development and implementation of the national virtual library, the NUC convened a stakeholder's workshop in Abuja in July 2001 where the blueprint for the project was developed and subsequently approved by the Federal Executive Council in January 2002. Eleven universities were selected as pilot centers for the first phase of the project, with the hub at NUC. A needs assessment for these eleven universities was also conducted. The necessary computer systems and digitization equipment were procured for NUC, who reported that since January 2002 when the National Virtual Library project was initiated, they had achieved the following:

i. recruitment of technical staff and consultants to meet manpower needs of the Project.

ii. Carried out a Rapid Needs Assessment in eleven (11) universities selected for the pilot scheme of the first phase of the project.

iii. Development and hosting of the Nigerian Virtual Library web site on the Internet with the URL: http://www.nigerianvirtuallibrary.com

iv. Digitization and uploading of journals published in Nigerian Universities. 
v. Aggregation of free international e-journals into the Nigerian Virtual Library for easy access.

vi. Open Tender process for the procurement, installation and maintenance of information systems for the eleven pilot universities and the hub in NUC inprogress.

vii. Training of university librarians and deans of faculties from Nigerian universities on the use and management of virtual library.

viii. Commencement of the process for electronic publishing of academic journals in Nigerian universities.

ix. Indexing of over 5,000 journal articles from all disciplines and on going.

x. Training of ICT officers in Nigerian universities on Webometric ranking of universities.

xi. Online and help desk assistance to users of the Virtual Library project.

As part of its efforts to successfully implement the Virtual Library project, NUC in conjunction with Virtual Library Consultants organized a series of training workshops to prepare the institutions and individuals for the successful deployment and management of digital libraries. The training workshops covered, but were not limited to the following areas: Web Technologies, Content Management, Access Management, Database Administration, Network Administration and Security.

Unfortunately, six years after the national Virtual Library Project was initiated and despite all the achievements enumerated by NUC and the series of training workshops, none of the eleven university pilot centers for the first phase of this project has begun operation and the National Virtual Library, which is now funded by the Educational Trust Fund (ETF) and is yet to be fully functional. In an effort to identify some of the problems that had hindered the development of the National Virtual Library, the researcher sought the views of some members of the team involved in the project. As some of the main problems, they cited lack of funds, lack of competent personnel with the technical knowhow of a virtual library, computer phobia, and lack of local resources for digitization. 
A critical review of the current National Virtual Library website http://www.nigerianvirtuallibrary.com/ reveals that there is a lack of understanding among the National Virtual Library team of what constitutes a virtual library and how to build it, which has contributed to the limited success of the project. This must have been a major factor that necessitated the transfer in February 2007 of the project to the Nigerian National Library which hopefully will make the project a reality and fulfill the purpose of establishing such a laudable project.

\section{Nigeria Information Technology Policy and Challenges for a Virtual Library}

Information technology policy is the catalyst for information transfer. The Nigerian government approved a national information technology policy in March 2001. The implementation started in April 2001 with the establishment of the National Information Technology Development Agency (NITDA), whose mission was to " use Information Technology for Education, Creation of Wealth, Poverty Eradication, Job Creation and Global Competitiveness". Two years after the establishment of NITDA, Uhegbu (2003), cited the unstable nature of Nigeria's economic and political environment; government apathy towards information services; weak and uncoordinated information professional associations in the country; oral medium of communication and high illiteracy rate; and underdeveloped and deficient information facilities in the country's information institutions as some of the problems hindering the implementation of the Information Technology Policy. Similarly, Oyesanya (2004) noted that there was a clear indication that NITDA had failed in the implementation of most of its core objectives and instead focused on holding a barrage of seminars on topics such E-Nigeria, E-judiciary and egovernment. Ukodie (2005) also asserts that five years after the establishment of NITDA, the Nigerian government has acknowledged the failure of the NITDA to implement the national information policy and has put in place a mechanism to review the policy. The failure of NITDA has also contributed to unsuccessful implementation of the Virtual Library initiatives. 


\section{Technological Challenges}

Building and sustaining a virtual library requires the proper technological infrastructure. This infrastructure includes telecommunication, servers, application platforms and software applications. Telecommunication infrastructure is a major factor in the deployment of Information and Communication Technology (ICT), particularly for the implementation of a virtual library. Nigeria has recorded a massive improvement in the telecommunication industry over the past few years. The Nigerian Communications Commission's regulatory efforts have led to increased competition and availability of a wide range of voice, data, and Internet applications and services. The improvement has led to the proliferation of Internet cafes in all parts of the country and this has also made a significant impact in all sectors - commerce, social and educational.

However, a lot still needs to be done. The lack of a national fiber network backbone infrastructure is a major issue in a successful implementation of the Virtual Library. Bandwidth and connectivity for higher education institutions and their Internet service providers are deployed using expensive technology like the VSATs, thereby reducing the number of higher education institutions that can benefit from the Virtual Library as well as eliminating its advantages. The erratic nature of electric power supply in Nigeria is another major problem that needs to be addressed for the successful implementation of a virtual library. Most Internet cafes and computer networks are run using generators which significantly increase the cost of Internet access. Providing a reliable electric power supply has to be part of the planning and deployment of a network infrastructure.

Maintaining web servers that host locally digitized materials and other digital resources hosted remotely as well as maintaining proxy access to restricted resources requires web technology skills. Dahl et al. (2006), assert that developing, installing and configuring web applications in a network environment requires an understanding of how the chosen network operating system handles the different levels of access privileges among users. Unfortunately, Nigeria has an acute shortage of digital/systems librarians and experienced web technology staff in libraries to install and manage technology networks (Ashcroft 
and Watts, 2004). In addition to the difficulties arising from the scarce technological skills to maintain the service, a web/proxy server needs to be up and running 24/7 and this is almost impossible with the erratic power supply.

\section{Roles of Nigerian Academic Librarians in Building a Virtual Library}

Virtual libraries are the future of academic libraries: they have brought about a completely different way of accessing information, thereby redefining the role of the libraries and librarians. Librarians with web technology skills will be required to facilitate skilled information retrieval, and to intervene between the user and the information to help users evaluate what they retrieve. Nigerian academic librarians, like other librarians in other parts of the world, are now faced with the challenges of acquiring web technology skills to augment what they traditionally learnt, to be able to contribute to the success of the Virtual Library.

The selection of materials for the Virtual Library is the sole responsibility of the librarian, hence the need for skills to identify and evaluate electronic resources. Managing subscriptions to electronic journals and negotiation of licences is another role the acquisition librarians would need to acquire. Apart from subscribing for electronic resources, librarians will need to also identify open access and free web-based materials that can also be included in the virtual library. They will also have to provide their patrons with help and assistance in finding, evaluating, and understanding the universe of information that the digital world provides. The implementation of a virtual library also implies that libraries will spend more money on hardware, software, licensing, training, and experts with web technologies skills to support and manage the library. Money will also be spent on translating content into digital form and facilitating access to the resources.

\section{Way Forward}

The following recommendations are made as a way forward to the actualization of the National Virtual Library project in Nigeria: 
i. The Federal government of Nigeria must as a matter of urgency improve the basic National Information Infrastructure, particularly electricity and telecommunication. The Government must also ensure the full implementation of the National Information Technology Policy. All virtual library initiatives must include librarians and information professionals, particularly subject specialists and collection development specialists who will be involved in selection and acquisition of electronic resources for the Virtual Library.

ii. Librarians and information professionals involved in building the Virtual Library should be trained in information and web technologies skills. With the dynamic nature of digital technology, they must constantly learn and retool in information and web development technologies through professional development, conferences and workshops.

iii. The Virtual Library should provide access to electronic resources, free web based resources, locally digitized resources, and open access resources.

iv. To help address the cost of electronic resources and proprietary software, the government of Nigeria should encourage the use of open source software and open access electronic resources.

v. Each higher institution should be provided with the enabling technology to access the Virtual Library.

vi. Libraries should seek more grants and other sources of funding to upgrade or establish the necessary information infrastructure.

vii. The shift in emphasis to access rather than ownership, the high cost of both hardware and software, and the lack of web technology skilled librarians make the formation of a library consortium very critical to building a successful virtual library project.

\section{Conclusion}

The growing number of higher institutions and poor funding by the Federal Government of Nigeria have implications for research and development, as research depends on having access to the current and relevant literatures. Having recognized the advantages associated with a virtual library, the Government has put in place policies and various 
initiatives to address this problem by starting National Virtual Library projects coordinated by NUC. The government must make a deliberate effort to provide funds for policy implementation, provide necessary technology training for librarians, and develop national information infrastructure or else the advantages associated with a virtual library will continue to elude us. The enabling technology infrastructure for building a virtual library must include stable electricity, and upgrading or installing a high speed Internet connection to support a variety of servers, such as web servers, proxy servers for remote access, FTP servers for uploading and downloading large files, with appropriate digital library software in each higher institution. Perhaps most important, systems/digital librarians with the required skills to manage and maintain this technology infrastructure need to be trained or employed.

\section{References}

Ajayi O.G. (2003). National Infrastructure and Support for a Virtual Library. Retrieved on 10/28/2006 from http://www.nitda.gov.ng/docs/papers/nitdavirtlib.ppt

Ani, E.O. (2005). Evolution of virtual libraries in Nigeria ; myth or reality?. Journal of Information Science, 31(1) 67-70. Retrieved on 11/22/2006, from http://jis.sagepub.com/cgi/reprint/31/1/67

Ashcroft L. and Watts C. (2004). ICT Skills for Information professionals in developing countries: perspective from a study of the electronic information environment in Nigeria . Retrieved on 11/30/2006 from: http://www/.ifla.org/V/iflaj/IFLA-Journal1-2005.pdf

Buckland, M. (1992) Redesigning library services: a Manifesto. Retrieved on 11/18/2006 from http://sunsite.berkeley.edu/Literature/Library/Redesigning/html.html

Cleveland G. (1998) Virtual libraries: definitions, issues and challenges. Retrieved on 11/25/2006, from http://www.ifla.org/VI/5/op/udtop8/udtop8.htm 
Dahl M., Banerjee K, and Spalti M (2006). Digital libraries: integrating content and systems. Great Britain: Chandos Publishing Limited.

Esselaar, S. and Stavrou, A. (2003). VSAT Case Studies( Nigeria \& Algeria ). Retrieved on 09/28/2006 from http://web.idrc.ca/uploads/user-S/10734864331vsatstudy.pdf.

Hanson A. and Levin L.B. (2003). Building a virtual library. Hershey PA : Idea Group Publishing Inc.

Lagoze, C., Krafft, D., Payette, S., \& Jesuroga, S. (2005). What Is a Digital Library Anymore, Anyway? D-Lib Magazine, 11(11). Retrieved on 11/06/2007 from doi:10.1045/november2005-lagoze.

National Universities Commission Executive Secretary's Office. Retrieved on 02/04/2007, from http://www.nucnigeria.info/es_office.htm

Oyesanya, F. (2004). NEED: adoption of a failing NITDA IT policy. Retrieved on $11 / 28 / 2006$,from

http://www.nigeriavillagesquare1.com/Articles/femi_oyesanya/2004_06_01_archiv es.html

Pitschmann, L. A. (2001). Building sustainable collections for free third party web resources. Washington, D.C.: Digital Library Federation, Council on Library and Information Resources. Retrieved on 10/20/2006, from http://www.clir.org/PUBS/reports/pub98/pub98.pdf .

Pettijohn, P. and Neville, T. (2003). Collection development for virtual libraries. In Building a virtual library. Hanson A. and Levin L.B (2003). Hershey PA :Idea Group Publishing Inc. 
Russell, B.S.P and Dlamini, H. (2002). Mission Report with the purpose of launching the Feasibility Study for the development of a virtual library for Universities and institutions of higher learning in Nigeria. Retrieved on 10/26/2006, from http://portal.unesco.org/en/file_download.php/92ad365dd2c83a23f4e626b8608ffeb $\underline{\text { 3Nigeria+Mission+Report.doc }}$

Tennant, R. (1999). Digital v. electronic v. virtual libraries. Retrieved on 09/26/2006, from http://sunsite.berkeley.edu/mydefinitions.html

Uhegbu, N .A. (2003). Constraints on the formulation and implementation of national Information policy for Nigeria . Journal of Information Science, 31(1), 41-47. Retrieved on 11/22/2006, from http://jis.sagepub.com/cgi/reprint/30/1/41

Ukodie, A. (2005). Government Review IT Policy. Daily independent newspaper. Retrieved 10/29/2006, from http://www.dailyindependentng.com/

Waters, D.J. (1998, July/August). What are virtual libraries? CLIR Issues, Retrieved 10/26/2006, from http://www.clir.org/pubs/issues/issues04.HTML

Ya'u, Z.Y. (2003). Towards a virtual library for Nigeria . Retrieved 06/29/2006, from http://portal.unesco.org/en/ev.php-

$\underline{\text { URL_ID=16043\&URL_DO=DO_PRINTPAGE\&URL_SECTION=201.html }}$ 